\title{
Analysis of Teaching Model of the Mathematic Course Innovation in Higher Vocational College
}

\author{
Ying Wei \\ Computer Department, Wuhan Polytechnic Wuhan, Hubei, 430074 \\ 915745208@qq.com
}

\begin{abstract}
Keywords: Informatization of vocational education; Mathematic course of vocational college; Teaching model; Case base; Micro-lecture videos
\end{abstract}

\begin{abstract}
The rapid-developed informatization of occupational education provides a great opportunity for the reform of higher occupational mathematics' teaching. Under the guidance of similar analysis and advanced occupational education theory, and with the integration of information technology and mathematics course, this paper presents an informatization self-exploration teaching model of higher occupational mathematics. In this model, the compatible case, the mathematics test question base, the micro-lecture videos and other kinds of informatization sources are established. This model will lead to higher vocational mathematics' teaching idea, teaching means and teaching structure toward more advanced and more scientific.
\end{abstract}

\section{Introduction}

Informatization of occupational education is the process that the teachers and the students of vocational education use the information technology and information resources based on the internet environment to promote the education teaching development and reform, to modernize the vocational education, and to meet the demand of era and society. Nowadays, the information technology is developing rapidly. The informatization of vocational education has made significant progress. Even ordinary vocational colleges have equipped enough computer and other corollary equipment. 90\% of them have constructed campus network which is running smoothly and fully functional. Their information technology has already been able to support the applications of the college education, teaching, management and research. The development and the application of digitalized teaching resources have also made important progress and the construction of the information resources platform and management platform are promoting steadily[1-2].

Information environment and abundant teaching resources have promoted the teaching and education reform, and provided the power to innovate the teaching of the higher vocation mathematics courses. Many mathematics teachers try to carry out teaching with the aid of information resources and multi-media technology. Via the practice they realized that using these technologies in mathematics teaching can help the students to understand the abstract conception and the hard knowledge, furthermore, to improve the teaching efficiency. But to integrate the text, the data, the diagrams, the images, the videos and other media, provide the students a multiple and interactive teaching environment platform, optimized teaching content structure, arouse students' interest, and finally improve education quality, the mathematics course teaching in the environment of informatization of vocational education shall be systematically and deeply researched. 


\section{Status of Related Research Work}

The integration of information technology and course teaching is an efficient path to innovate the course teaching in the environment of the informatization of occupational education. It's a new teaching type which coordinately combines the information technology, resources, methods, manpower resources and course content in the process of course teaching, and accomplish the teaching mission. As an important basic subject in vocational colleges, mathematics course plays an irreplaceable role in the aspect of developing students' comprehensive quality and professional skill. But in consideration of the vocational college students' lacking of mathematics foundation, abstract thinking ability and capacity of generalization, the effect of simple classroom teaching is not as ideal as expected. Although vocational educators has made beneficial trial to innovate the mathematics teaching, the traditional teacher-oriented and cramming teaching method hasn't changed thoroughly. The students feel that mathematics is baldness, abstract and hard to understand. This kind of teaching model is not benefit to the developing of the students' mathematics quality and creative thinking, and does not meet the require from the career to the mathematics course.

We try to found an ideal study environment by coordinately integrating the mathematics course and the information technology. In one aspect, the media technology was properly used in the class to create a learning situation, arouse the students' great study interest, make the classroom teaching more suitable for the students' psychological feature and cognitive rules, make the students always acquiring direct, vividly and perceptual knowledge more actively in a relaxed and pleasant mood. This will make mathematics knowledge which is abstract and hard to understand absorbed right in the class and improve the classroom teaching result. In the other aspect, this kind of environment supports foundation of real situation, and has a resource sharing which is not effected by the time and area and a various interactive mode. That makes the learners break the limit of areas to cooperate and communicate, and obtain information rapidly and neatly. And it's benefit for cultivating the learners' quality of creatively inquiring and discovering by themselves.

In recent years, many vocational college teachers engaged in relative researches. For example, in 2005, Xiao Zhaowu from Xiangyang vocational and technical college researched the integration of the media technology, network technology, virtual reality technology and the vocational mathematics teaching according to certain teaching theories and principles. In 2012, Zhang Hongwei from Hunan electrical vocational and technical college fully used the information technology, followed the "necessary and sufficient" principle, the "double subjects" principle, the revealing mathematics teaching features principle, the information technology instrumentalization principle and the teaching effect optimization principle to research the integration of the information technology and vocational mathematics teaching in the guidance of vocational education theories, mathematics teaching theories and constructivism theories. Besides, there were lots of education professors and vocational college teachers who had made positive research and exploration to the application of information technology on the reform of vocational mathematics teaching. Yet, the systematic study on the reform of vocational mathematics teaching in the background of education informatization is still lacking, and the advantages of vocational teaching informatization on aspect of mathematics course teaching are not reflected [3-6].

\section{Research Content of Vocational Mathematics Teaching Model}

In the background of current status of vocational mathematics teaching, we have to integrate the modern information technology and vocational mathematics course under the guidance of advanced theory of vocational education and mathematics teaching and supported by constructivism. In order to turn the passive learning into active learning namely self-exploration and co-operation study, we shall use information technology such as computers, multi-media, internet and mathematics software and so on as supplementary tools which can motivate the students and help them to perceive, and also build up the data base for the digital study. The self-exploration teaching model of higher vocational mathematics can thus be structured with masterstroke on the students' self exploration study which 
led by the teachers, completed by the students themselves and competence-oriented in the background of vocational education informatization.

(1) Establish the teaching system of higher vocational mathematics with the guidance of constructivism in the background of vocational education informatization

With thorough consideration of the characteristic of higher vocational mathematics in the context of technical major feature mixed teaching model we have deconstructed and reconstructed the higher vocational mathematics course to three parts which closely integrated with the majors namely the basic course for all majors, obligatory course for specific courses and further study course according to the requirement of the electromechanical, computer science and business management major courses. Based on that with constructivism we can integrate the information technology course and higher vocational mathematics course on the platform of informatization of vocational education. That means using teaching tools such as computers, multi-media, internet, mathematics software and so on, inspiration tools and students' ignition tools we can build up a self-exploration teaching model in the context of informatization of vocational education which led by the teachers, completed by the students. In short, it contains five steps: providing a scene, raising questions, self-exploration, query and rethinking, further study and making progress. The advantage of information technology which makes the abstract things specific, complicate things simple, and deep theory straightforward for the students to interact with the teachers with all kinds of digital tools can lead the students into the study scenes efficiently. The photos, animation, internet, such kind of visual material can make up for the lack of imagination of the students and help them to solve the key and difficult points and finally reach their study goal [7-8].

(2) Collection cases in the database in the higher mathematics teaching system in the context of informatization of vocational education

As an innovative, positive teaching method of case teaching can lead the students to think, learn with questions, learn how to study and find new knowledge. In the classroom the teachers as the organisors and tutors shall use the cases closely connected with students' majors or the daily life to draw the students into the mathematics concepts and knowledge in order to lead the students learn with questions and be more enthusiastic with the study. Furthermore, some cases can be used to consolidate the learning and enhance the practice ability. We plan to estalish a case database closely connected with major such as electrics, mechanics, business and daily life, so that the teachers of different majors can choose cases from the database freely. Using information technology like the case database can present the mathematics course to the students in a new appearance, inspire them to study, enhance the practice of mathematics and promote their mathematics sense.

(3) Making micro-lectures for the learning using information technology

Micro-lecture is small lectures of interpretation of study points or teaching link made into videos released on internet supporting multiple study ways. Using the micro-lectures in the teaching is tendency of combination of information technology and courses. In the mathematics classroom we can integrate the micro-lectures into the teaching. For example, before we explain an abstract concept we can raise up a practical question with the micro-lectures, in addition with background music, funny photos, humorous description that can simplify and specify the questions and build up a relaxed environment for the students to learn. For the micro-lectures of some key and difficult mathematics points we can design with mathematics software, show with geometric drawing and animation, sound and texts. These micro-lectures can help the students review and consolidate some knowledge and skills, so that their efficiency and accuracy can be promoted. Furthermore, the multi-media can provide database to the students to practice, review and test their mastery. The micro-lecture can fulfill all kinds of need of the students because they can be used in and after the class [9]. 


\section{The practice and theoretic meaning of teaching model of higher vocational mathematics}

(1) This research can cultivate the teachers' education concept of informatization which enables the them to explore the new way of teaching in the context of informatization based on the original traditional teaching experience, combine all kinds of teaching practice with information technology, guide and mix their teaching with education concept of informatization. And then the teachers become the leaders, cooperators and organisors of students.

(2) The course standard and outline made from the self-exploration teaching model of higher vocational mathematics in the context of informatization of vocational education in this research can provide the theoretic base for the higher vocation mathematics course reform.

(3) The databases of micro-lectures, mathematics casing and exercise in this research can work as a great supplementary for the higher vocational mathematics teaching and online resource, and also as a great example for course reform of other higher vocational colleges.

(4) Providing a scene, raising questions, self-exploration, query and rethinking, further study and making progress, this kind of higher vocational mathematics teaching model can improve the quality of the course and competent people, and heighten students' interest, innovation spirit and ability.

(5) The informatization teaching will be with the help of the platform of informatization system to share the informatization teaching resource. It indicates thus the teaching concept of vocational education "led by the teacher, completed by the students"in the teaching activity of "learning while doing, doing while learning, doing while teaching”.

\section{Some questions of informatization teaching}

(1) More input on the development and enlargement of the multi-media course database.

Currently there are plenty of teaching material, mathematics casing and exercise database, and micro-lectures we researched and developed for the teachers to use in the classroom or the students to learn by themselves. But the course ware and teaching resource that can help the teachers and students interact with each other are in lack. Therefore, the teachers shall work with education experts and computer technical workers to develop more mathematics resource fit into the higher vocational mathematics course.

(2) To be cautious of the abuse of the information technology

The the combination of information technology and high vocational mathematics teaching forms a brand new teaching model which gives the traditional teaching dynamic. But it dose not mean the traditional teaching namely the blackboard plus chalk is worthless because the calculation procedure needs to be presented on the board and explained by the teachers to make the students easy to understand. On the contrary, if we turn the content on the blackboard into multi-media course ware, it is "go by the book" style and the effect won't be good.

In conclusion, in the context of vocational education informatization we can integrate the modern and traditional teaching methods as supplementary and bring out the best in them through the combination of information technology and higher vocational mathematics course. It can on one hand optimize the course structure, strengthen the learning interest, improve the teaching quality, on the other hand the characteristic of computer internet namely the share and overtime enables the students to share the study resource equally and provide a widely study space for the their self-study.

\section{Acknowledgments}

This work is supported by the 2014 key project of Education Science "Twelfth Five-year" Plan of Hubei province (No. 2014A071). 


\section{References}

[1] R.Y. Fan, X.L. Xiang, Vocational and Technical Education (Education Science) 24 (2003) 57-60.

[2] H.W. Zhang, G.Y. Zhou, Journal of Yangtze University(Natural Science Edition) 9 (2012) 143-144.

[3] Z.W. Xiao, Journal of XiangFan Vocational and Technical College 4 (2005) 101-104.

[4] Y.M. Lang, D.T. Zhou, Vocational \& Technical Education Forum 11 (2005) 16-18.

[5] F.G. Deng, Course Education Research 25 (2013) 130-131.

[6] Y. Wei, Journal of Changsha Telecommunications and Technology Vocational College 11 (2012) 130-132.

[7] S. Jiang, Journal of Wuhu Institute of Technology 2 (2010) 72-73.

[8] C.P. Dai, Occupation Space 6 (2013) 36-38.

[9] C.J. Rao, Journal of Huanggang Normal University 29 (2009) 63-66. 